\title{
The Semantics of Spatial Demonstratives in Spanish: A Demonstrative Choice Task Study
}

\author{
Todisco Emanuela* ${ }_{1}$, Roberta Rocca, Mikkel Wallentin 3 \\ *corresponding author: e.todisco@uib.es \\ ${ }_{1}$ Universitat de les Illes Balears, Facultat de Filosofia i Lletres, Departament de \\ Filologia Espanyola, Moderna i Clàssica (Spain).
}

${ }_{2}$ Aarhus University, Interacting Minds Centre (Denmark); University of Texas at Austin, Department of Psychology (US).

3 Aarhus University, Department of Linguistics, Cognitive Science and Semiotics; Aarhus University Hospital, Centre of Functionally Integrative Neuroscience; Interacting Minds Centre (Denmark)

\begin{abstract}
Demonstratives (this/that in English) are pivotal in communication. In this study, we show that semantic features of referents systematically influence speakers' choices of demonstrative forms for Spanish nouns in the absence of a guiding context. We used the Demonstrative Choice Task (DCT), previously applied to two-term demonstrative languages (Danish, English and Italian), and applied it to Spanish, a three-term demonstrative system (este/ese/aquel), to test if the semantic dimensions driving demonstrative choice overlap with those found for English. 1639 native Spanish speakers were presented with 480 nouns rated along 76 semantic features and were asked to match each noun with a demonstrative. We found that demonstratives are influenced by the same semantic factors as two-term languages, such as manipulability, valence and the self. In Spanish, these semantic factors predict the demonstrative choice between the proximal este/a and a combination of medial and distal forms ese/a and aquel/la. Additional semantic factors affect speakers' preferences for ese/a versus aquel/a (e.g., visuality and time). We conclude that many of the semantic attractors influencing the choice of demonstratives are constant across languages, independent of the number of terms characterizing the demonstrative system, and provide a window into the landscape of meaning subserving linguistic reference.
\end{abstract}

Keywords: Spanish spatial demonstratives; semantics; DCT; cross-linguistic. 


\section{Introduction}

\subsection{Spatial demonstratives as deictic expressions}

Demonstratives (this/that in English) are cross-linguistically widespread deictic expressions. They are crucial for conveying information about space, time, person and discourse in exophoric and endophoric contexts (Diessel, 1999, 2005; Diessel \& Coventry, 2020), as well as to manipulate the interlocutor's focus of attention during interaction (Kita, 2003; Rocca, et al., 2019b; Todisco, et al., 2020).

Demonstratives are among the most frequent and flexible words in the lexicon (Diessel, 2013, 2014; Leech, et al., 2014). In different situations, expressions such as 'This one' may refer to an object, a person, an event or a thought. The advantage of such flexibility is that demonstratives can be used in a variety of linguistic and pragmatic contexts. The disadvantage that follows is that uttering a demonstrative will not always ensure identifiability of the intended referent, as the following examples show. In the sentence 'This is what I think about you: you are a lovely person', the cataphoric use of the pronoun this is disambiguated and easily identifiable by the sentence that immediately follows (i.e., you are a lovely person). Nevertheless, in the sentence 'Give me that thing', the adjectival use of that is not easily identifiable without additional cues. These cues are usually provided by nonverbal components of the context of utterance, among which pointing gestures and eye-gaze trajectories (Kita, 2003; Talmy, 2018; Todisco et al., 2020).

Combining verbal and nonverbal referencing strategies, that is, pointing and gazing at a specific referent while using a demonstrative, facilitates the task of disambiguating the referent, compared to contexts where the speaker only uses one modality, either verbal or nonverbal (Cooperrider, 2016; Fricke, 2014; Iverson et al., 2000; Kita, 2003; Todisco et al., 2020). Talmy $(1983,1988)$ and Kemmerer (2006, p. 1608) highlighted that demonstratives alone do not encode precise degrees of remoteness from the speaker (or deictic centre). Sentences like 'Here in this room' and 'Here in this galaxy' are both perfectly grammatical, despite the huge differences in scale, because the semantic space demonstratives carve is pragmatically modulated by the combination of nonverbal cues, communicative intention of the speaker, physical position and salience of referents in the contextual communicative scenario (see Diessel \& Coventry, 2020; Kemmerer, 2006, p. 1608). Moreover, the choice of one specific demonstrative rather than another 
also conveys some disambiguating information about the intended referent. In the utterance, 'I know that guy', for example, the use of that - rather than the perfectly grammatical alternative this - hints at the referent being located at some physical or social distance from the speaker (Peeters, et al., 2020; Rocca, et al., 2019a; Rocca \& Wallentin, 2020).

In the present study, we aim at clarifying the role of the semantics of referents in the choice of demonstrative forms used to indicate them, using a simple and versatile experimental paradigm called the "Demonstrative Choice Task" (henceforth: DCT). Previous studies have used this paradigm to investigate semantic factors driving demonstrative choice in English (a two-term demonstrative system with this/these as proximal forms and that/those as distal forms; Rocca \& Wallentin, 2020) and other twoterm European languages (Danish and Italian, though only a small number of semantic dimensions were investigated for these languages; Rocca \& Wallentin, 2019a). In this study, we use the DCT to delve into the semantics of demonstrative choice in Spanish, a language with three demonstrative forms (este, this/ese, this-that/aquel, that). Comparing patterns of demonstrative use in the DCT for Spanish with findings for a two-term language, such as English (this/that), will contribute to shedding light on whether similar clusters of semantic dimensions drive demonstrative choices across languages, even when languages differ in number of terms available in their demonstrative systems. Furthermore, results from this study will allow us to gather insights on whether the use of medial demonstrative forms (i.e., ese) versus distal ones (i.e., aquel) can be explained by specific semantic dimensions of the referent, or whether, from a semantic perspective, medial forms are entirely redundant with distal ones.

\subsection{Perceptual vs. psychological factors influencing demonstrative choice}

The speaker's choice of a specific demonstrative form results from a complex process of resolving the mappings between a number of multimodal perceptual, attentional, and pragmatic cues in the minds of both the speaker and the hearer and their relations to the intended referent. Cues functional to identifying the referent can largely be categorized as perceptual or psychological factors. Perceptual cues are those pieces of information contributed, for example, by the physical circumstances of the utterance. Distance between the referent and the speaker is perhaps the most intuitive one, and the 
most widely studied and debated. Distance modulates the choice of demonstrative based on a near/far dichotomy (Di Pellegrino \& Làdavas, 2015), such that the chosen form encodes information on whether the referent is proximal or distal from the speaker (or deictic centre). Many studies have pointed to space and distance between speaker and referent as being the most prominent parameter determining speakers' choice of a specific demonstrative form (Diessel, 1999, 2005, Caldano \& Coventry, 2019; Coventry, et al., 2008; Hunley \& Lourenco, 2018).

In the context of these studies, distance is often understood as a physical space separating the speaker and the referent. However, a recent work by Bocale and Cologna (2020) has pointed out that distance in communication should be better understood as incorporating a variety of subjective factors. An adequate notion of distance does not merely resolve in an indicator of physical space, but is a complex notion which incorporates both absolute and perceptional/perspectival distance relationships between interlocutors. Absolute distance in this terminology is the space between two discourse elements, such as the speaker and the intended referent. Perceptional/perspectival distance includes a displaced reference point, such as the perspective of the hearer involved in the communicative interaction (see Rocca et al., 2019b).

Distance is thus a prominent, but not the only perceptual factor affecting the choice of demonstratives. It has been pointed out, for example, that visibility of the referent may also systematically influence demonstrative choice, as shown by Coventry and colleagues (2014) in a study using an adapted version of the psycholinguistic elicitation paradigm known as the 'Memory Game for Object Location' (Coventry et al., 2014). In this study, adult English monolingual speakers were asked to point to and verbally describe the position of disks placed at varying distances, with the visibility of disks being manipulated by covering them with either an opaque or a clear container. Results showed that the proximal demonstrative form this was used less often when the objects were covered with the opaque container, meaning that whether the object is visible or not also affects demonstratives choice and usage.

Alongside perceptual cues provided by the context of the utterance, the mapping between demonstratives and referents is also mediated by psychological factors, which depend on more abstract, cognitive processes, such as memory and emotions, rather than on perceptual ones. Social proximity between speaker and hearer, and the perspective of the hearer (Küntay \& Özyürek, 2002; Peeters, et al., 2015; Peeters, et al., 2020), for example, can determine whether the speaker chooses a proximal, medial or a 
distal demonstrative form. Knowledge of the functional status of the referent (i.e., its affordance for manual grasp, see Coventry et al., 2008; Coventry, et al., 2014; Rocca, et al., 2019a), as well as whether or not the referent is within or outside attentional focus (Strauss, 2002), are other psychological factors explored in the literature.

Evidence for the role of a variety of perceptual and psychological factors in speakers' choices of demonstrative forms (and, therefore, in reference resolution on the addressee's side) does not necessarily entail that all of these parameters do always (or always equally) play a role in speakers' demonstrative choices or in the identification of the intended referent. A strict one-to-one correspondence, e.g., one specific parameter fully describing demonstrative choice in a specific language, is reductive and may lead to a misinterpretation of how the identification of the intended referent works.

Parameters are not mutually exclusive; a range of potentially relevant parameters is available to the speaker and hearer, from which they select the most salient ones in accordance with the information they want to convey or with communicative needs/constraints (Todisco et al., in preparation; Peeters, et al., 2020). This combination of systematicity and flexibility is what makes demonstratives such an efficient, pervasive, and cross-linguistically widespread communication tools: all languages have some demonstrative forms, although the number of demonstrative terms and parameters affecting demonstratives choice can vary (Diessel, 2005, 2013; Diessel \& Coventry, 2020; Levinson et al., 2018). Providing a full description of which factors drive demonstrative choice and use, how their importance is modulated by context, and the extent to which these dynamics generalize across languages thus provides a key contribution to unpacking the pivotal mechanisms underlying the complex functioning of linguistic reference in interaction (Peeters, et al., 2020).

In this study, we delved into a fundamental conceptual and psychological factor of demonstratives: their semantics. The relationship between semantics and deixis has been extensively discussed in previous literature, but, as highlighted by Dufter (2015), a great part of these studies focus on the interface between semantics and pragmatics in discourse (e.g., the function of deictic expressions in discourse, or the role of speaker's intentions in producing a deictic reference), and they mostly use qualitative tools. However, semantics and demonstrative reference are interwoven at a more fundamental level. The choice of demonstrative forms may in fact be constrained by which entities they are meant to refer to, especially when no other additional contextual cues, such as addressee position or physical distance, are provided. The semantics of such entities 
(and, thus, of the nouns denoting them) influence which demonstrative form are used, and, in turn, the use of specific demonstrative forms and/or their position provides information about the referring noun and/or the intended object (Jungbluth \& Da Milano, 2015).

Previous studies on the semantics of demonstratives have mostly focused on a few selected, hypothesis-driven semantic factors at a time, or as embedded in interaction and physical space. Paradigms like the David Wilkins Demonstrative Questionnaire (DWDQ, 1999), the Memory Game for Object Location (Coventry et al., 2014) and conversation data collection (Küntay \& Özyürek, 2002) are example of elicitation methods used to investigate factors driving demonstrative choice (see also Levinson, et al., 2018 for a cross-linguistic detailed review). The DWDQ manipulates 25 parameters - among which: distance, interlocutors' focus of attention, visibility, possession and mention of the referent during conversation - while assessing one factor at the time (Lin Lin, 2013; Wilkins, 1999). Coventry and collaborators (2014) assessed that ownership, during the Memory Game paradigm, was affecting demonstrative choice and resulting in a larger use of this.

Thus, while perceptual factors and single psychological factors have been widely explored and debated, and differences in their role across languages extensively discussed (Levinson et al., 2018), the role of semantics in demonstratives choice has only recently started to receive attention in the experimental literature (Rocca et al., 2018, 2019a, b; Rocca \& Wallentin, 2020). The first attempt to provide a comprehensive overview of the semantic dimensions on demonstrative choice which both isolates the contribution of semantics from perceptual and pragmatic factors and probes the role of a large set of psychologically relevant dimensions was provided by the online questionnaire paradigm DCT (Rocca et al., 2018, 2019a, b; Rocca \& Wallentin, 2020).

\subsection{The Demonstrative Choice Task: mapping the role of semantics}

Rocca and collaborators (Rocca et al., 2018, 2019a, b; Rocca \& Wallentin, 2020) studied the effect of semantic features of concrete referents/nouns in demonstrative choice for two-term demonstrative systems. By asking participants to match nouns and demonstrative forms without priming them with any contextual cues, they showed that speakers of different European languages (English, Danish and Italian) converge on 
using proximal demonstratives when referring to words denoting harmless, familiar objects (like apples), and distal demonstratives for harmful, threatening objects (such as tigers). Moreover, Rocca and collaborators (2019a) found that manipulability of the intended referent, a semantic dimension combining both perceptual (size), psychological (harmfulness) and ontological (animacy) dimensions of the intended referent, influences the choice of a proximal demonstrative (i.e., this) over a distal form (i.e., that) in two-term demonstrative systems, such as English, Italian and Danish. In a subsequent study including a larger number of both words, semantic dimensions and participants (Rocca \& Wallentin, 2020), it was found that demonstrative choice of the English proximal form (i.e., this) over a distal form (i.e., that) was related to a set of additional semantic factors, including valence, arousal, loudness, motion, time and more generally, the self as a multidimensional perceptual and psychological construct.

The results reported by Rocca and collaborators suggest that demonstrative choice depends on the interaction of a number of semantic features of a referent relative both to the speaker's physical and psychological spaces. More specifically, objects can be closer or further away in space, but also in time (e.g., this time), or phenomenologically and emotionally (e.g., Don't be that guy) (Rocca \& Wallentin, 2020; Peeters, et al., 2020). Distance is evaluated not only relative to the physical anchoring of the speaker in the immediate perceptual space, but also, in what Bühler (1934/2011) and Stukenbrock $(2014,2015)$ define as 'Deixis am Phantasma', relative to the position of the speaker in an imagined space. The dynamic deictic displacements have been described by Stukenbrock (2014) as a continuous shifting of origos among physical and psychological reference spaces and dimensions. When no physical distance information can be or needs to be conveyed, the reference space becomes an imaginary one, organized around dimensions such as familiarity and affection (e.g., sociocentric parameter in demonstrative choice, Peeters et al., 2015; Peeters, et al., 2020). In line with this, the DCT results suggest that the imagined space is organized around the self and its needs and motivations. The notion of self conflates the function of physical, bodily and psychological reference spaces into one multidimensional hyperspace, and the referent's location within this space is what determines the choice of one demonstrative over another.

While the results from large-scale DCT studies in English (Rocca et al., 2019a; Rocca \& Wallentin, 2020) are reliably consistent across participants, no evidence exists yet that these patterns generalize to the dynamics of demonstrative use across languages 
which differ in their demonstrative inventory. One of the strengths of the DCT paradigm, however, lies in the possibility of seamlessly adapting it to different languages, regardless of the number of demonstratives a specific system has. Showing that semantic patterns replicate not only in languages with two-term demonstrative systems, but also across languages with more than two demonstrative terms, would provide a strong argument supporting the hypothesis that these mechanisms capture a fundamental aspect of the relation between human cognition, semantics and linguistic reference. This is the rationale behind the present study, where we extended the DCT study by Rocca and Wallentin (2020) to Spanish, in order to both probe the replicability of the results obtained so far, and to characterize the role of additional demonstrative forms, such as medial forms in the Spanish three-term system, in the interplay between demonstrative reference and the self.

\subsection{Demonstrative terms in Spanish}

Spanish has a three-term demonstrative system which consists of a proximal form, este/a (this), a medial form, ese/a (this/that), and a distal term, aquel/la (that). The three terms present masculine and feminine, as well as singular and plural, forms which convey gender and number information in accordance with the noun they accompany (adnominal demonstratives: e.g., esta luna, this moon) or substitute (e.g., estos, these, referring to the plural referents 'books'). The proximal-medial-distal distinction has been suggested to designate increasingly remote concentric circles around the speaker (Hottenroth, 1982, p. 133). Traditionally, the adnominal/pronominal proximal form este/a (this) has been said to identify a portion of space close to the speaker; the medial form ese/a (this/that) identifies a medial distance from the speaker (or hearer), and aquel/la (that) is used for portions of space located far away from the speaker (and hearer). This division is partly supported by experimental evidence (Coventry et al., 2008). Using the Memory Game for Object Location (Gudde, et al., 2018), Coventry and collaborators (2008) found that speakers of Spanish also tend to carve up space along a peri-personal (within reach) versus extra-personal (outside reach) distinction. Participants used more instances of the proximal demonstrative este/a (this) in the peripersonal space compared to extra-personal space. Interestingly, however, Coventry and colleagues did not look at the distinction between usage patterns of the medial (ese/a) and the distal (aquel/la) demonstrative in the extra-personal space - which therefore 
remains largely unexplored. Moreover, in the majority of the abovementioned studies, semantic distinctions between referents are 'controlled for' or neutralized rather than thematized as a factor of interest (Coventry et al., 2008; Jungbluth, 2003). To our knowledge, there is no empirical study systematically and comprehensively describing the use of Spanish demonstrative forms as a function of semantic features of the referent when no contextual cue is provided and without the interaction with an addressee.

\subsection{The present study}

In the present study, we used the DCT to investigate the relationship between semantics and demonstrative choices in Spanish.

The aims of this study were twofold. First, we aimed at investigating whether and how semantic features influence demonstrative choices in a language with a three-term demonstrative system. We expected to replicate results from the English two-term system, with semantic features related to referent manipulability, valence and to a psychological notion of 'self' driving preference for proximal vs. other forms (cf. Rocca $\&$ Wallentin, 2020). To this end, Spanish data were collected for the same set of words used in this study. These words comprised a set of words, previously given comprehensive semantic annotations by Binder and collaborators (2016). Secondly, we aimed at exploring usage patterns and potential semantic specificities of medial and distal forms (i.e., ese/a and aquel/la in Spanish) in contexts where fine-grained spatial distinctions are not needed. With respect to the latter, two possible scenarios could be expected. In contexts where conveying precise information on the referent's physical location is not necessary, the distinction between medial and distal forms could:

a) disappear, leading to a collapse onto a binary near/far opposition. If this were the case, we would expect to see either a random distribution of the two non-proximal demonstratives, or a diminished use of one of the two non-proximal demonstratives, most probably the distal form aquel/la (that) in favour of the medial form ese/a (thisthat), in line with a trend of reduction already identified in Argentinian Spanish (Pérez-Saldanya, 2015) and the Majorcan Catalan (Todisco, et al., 2021).The Argentinian Spanish three-term system (este, this/ese, this-that/aquel, that) is in fact characterized by the coexistence of the two forms ese/a and aquel/la for the same dimension (the medial/distal space), where the distal demonstrative aquel/la is 
considered more formal than the medial demonstrative ese/a (Pérez-Saldanya, 2015, p. 116) but semantically equivalent. Majorcan Catalan demonstratives system (aquest/aqueix/aquell) presents a reduction to two-terms (aquest/aquell) when information about physical distance is conveyed (Todisco et al., 2021).

b) adapt to specific semantic factors and dimensions. The choice of the medial ese/a versus the distal term aquel/la could be made on the basis of semantic factors. In other words, speakers may use a multidimensional mapping between demonstratives and semantics, such that particular semantic dimensions map onto the medial/distal gradient of ese/a-aquel/la, while other dimensions may map onto a proximal/non proximal gradient of este/non-este.

\section{Materials and methods}

\subsection{Participants}

Similar to Rocca and Wallentin (2020), we conducted a DCT experiment using Qualtrics (http://qualtrics.com) with participants recruited through the website Prolific http://prolific.ac (see Appendix B for an example of the experiment). 1639 native Spanish speakers participated (gender: 871 female, 746 male, 22 other; age information was collected in bins: 1013 were 18-30 years, 401 were 30-40 years, 161 were $40-50$ years, 56 were $50-60$ years, and 8 were $60+$ years). The study was approved by the Institutional Review Board at Aarhus University.

\subsection{Procedure}

The study took on average 719 (std: 479) seconds to complete, and participants were rewarded with 0.9 GBP for participation. Each participant was presented with 60 Spanish words, sampled and translated from a database of 535 English words rated on 65 different semantic dimensions comprising sensory, motor, spatial, temporal, affective, social, and cognitive experiences (Binder, et al., 2016). 480 of the 535 words were divided into 8 subsets, and participants were presented with one such subset of words in a pseudorandomized manner. Translation of the full list of words from English to Spanish is presented in Appendix C. To allow for comparison with English, we used the same words (translated in Spanish). We provided both masculine and feminine forms for both the noun and the demonstrative options (i.e., noun: professor/a, teacher; 
demonstrative options: este/a, this; ese/a, this-that; aquel/la, that), or only for the demonstratives when the noun had the same form for both feminine and masculine form (i.e., common gender noun: paciente, patient; demonstrative options: este/a, this; ese/a, this-that; aquel/la, that). In total, we had 57 occurrences of masculine/feminine words, 26 occurrences of common gender nouns; 188 occurrences of exclusively feminine nouns and 209 of exclusively masculine nouns. Grammatical features of the nouns were in accordance with the linguistic regulation of the Real Spanish Academy (Real Academia Española: https://www.rae.es). Similar to previous experiments (Rocca, et al., 2019a; Rocca \& Wallentin, 2020), participants were asked to couple each word with a proximal, medial or distal spatial demonstrative, such as este/a, ese/a, or aquel/la without further context. Demonstrative gender was congruent with the individual words. Participants were instructed to simply follow their intuition and choose the combination of demonstrative and word they thought fitted best. Subsequently, participants were subjected to a short personality test, and two tests of mood. Analysis of these data falls within the scope of a separate study (ongoing) and will not be reported here.

\subsection{Materials}

The 65 semantic dimensions that words are rated along in the Binder dataset are: Vision, Bright, Dark, Color, Pattern, Large, Small, Motion, Biomotion, Fast, Slow, Shape, Complexity, Face, Body, Touch, Temperature, Texture, Weight, Pain, Audition, Loud, Low, High, Sound, Music, Speech, Taste, Smell, Head, UpperLimb, LowerLimb, Practice, Landmark, Path, Scene, Near, Toward, Away, Number, Time, Duration, Long, Short, Caused, Consequential, Social, Human, Communication, Self, Cognition, Benefit, Harm, Pleasant, Unpleasant, Happy, Sad, Angry, Disgusted, Fearful, Surprised, Drive, Needs, Attention, and Arousal. The database is publicly available here: http://www.neuro.mcw.edu/representations/index.html, and the rationale for the choice of these exact features is that they represent "experiential phenomena for which there are likely to be corresponding distinguishable neural processors" (Binder, et al., 2016). The notion that these features should have clearly defined neural underpinnings suggests that they are somehow important and representative for human cognition (see Binder et al., 2016 for further details).

Similar to Rocca and Wallentin (2020), we also included the Lancaster Sensorimotor Norms (available here: https://osf.io/7emr6/) to our feature set to improve the semantic profile on manipulability. This dataset provides ratings along 11 sensorimotor features 
for a large body of words (Lynott, et al., 2020). The 11 dimensions are the following (the affix Lan is appended to differentiate from features from the Binder dataset): Auditory_Lan, Gustatory_Lan, Haptic_Lan, Interoceptive_Lan, Olfactory_Lan, Visual_Lan, Foot_leg_Lan, Hand_arm_Lan, Head_Lan, and Mouth_Lan (see Rocca and Wallentin 2020 for illustrations of the features ordered according to semantic factors, obtained by factor analysis).

The overlap between the stimulus words and the two databases included 472 out of the original 480 word. All feature ratings were standardized to make them comparable. Two Binder features contained missing ratings for particular words. These were imputed using the mean of all other words along that feature.

\subsection{Statistical analyses}

Analyses were conducted in RStudio version 1.1.383 (RStudio Team, 2016) running $\mathrm{R}$ version 4.0.2 ( $\mathrm{R}$ Core Team, 2020). Additional packages were used: tidyverse 1.3.0 (Wickham et al. 2019), xlsx 0.6.3 (Dragulescu \& Arendt, 2020), psych 2.0.7 (Revelle, 2017), ggsci 2.9 (Xiao \& Li 2018), cowplot 1.0.0 (Wilke 2020), reshape2 1.4.4 (Wickham 2020), scales 1.1.1 (Wickham et al. 2020), and MBA 0.0.9 (Finley et al. 2017).

The analysis involved the following steps made in order to replicate the analyses conducted by Rocca and Wallentin (2020) while also adapting the procedure to a threedemonstrative language:

1. Exploratory factor analysis on independent variables (semantic features) to lower dimensionality and create independent semantic dimensions (identical to Rocca \& Wallentin 2020).

2. Aggregating demonstrative choices, i.e. determining proportion of the choice of este/a, ese/a and aquel/la for each word. Conducting principal component analysis on the proportions. This turns the three options into two dimensions (i.e. two principal components (PCs)), which correspond to the effective degrees of freedom in a three-choice experiment. This adapts the analyses conducted by Rocca and Wallentin (2020) to the Spanish case.

3. Conducting two regression analyses, one for each PC, using semantic factors to predict the PC scores for each word. 
Each of the steps is described in details below. Data and analysis scripts are available at Open Science Framework (https://osf.io/hjgfb/).

\subsection{Exploratory factor analysis of semantic features}

We used the same dimensionality reduction approach to the semantic space (i.e., the 76 semantic features) as that used by Rocca and Wallentin (2020). This was aimed at lowering the number of correlated regressors to be used in statistical analyses while preserving structural factors of the semantic space. To determine the number of latent factors, we used Horn's parallel method (Horn, 1965), implemented in the psych package (Revelle, 2019) in R. This method compares the scree plot from the observed data with one made from random samples (randomized across rows) of the original data, and subtracts out the components that explain less variance than a comparable factor based on non-informative data. The estimated number of non-random factors in the semantic features using this procedure was 12 . Factor analysis was conducted using Ordinary Least Squares (OLS) to find the minimum residual (minres) solution. Orthogonal rotation (varimax) was applied to maintain orthogonality among factors (important for use in regression analyses). The cumulative proportion of variance of the semantic features explained by the 12 factors was 0.75 .

The same factor labels as those used by Rocca and Wallentin (2020) were applied (see figures 1-3). The 12 factors and the proportion of the variance they explained in the original semantic space were: Vision (0.14), Valence (0.11), Loudness (0.09), Human (0.06), Taste/Smell (0.06), Motion (0.06), Manipulability (0.06), Scene (0.05), Time (0.03), Torso/Legs (0.03), Arousal (0.03), Self (0.03). It is important to note that these factors and the relative variance they explain do not necessarily reflect the general distribution in language or semantics, but only in the underlying sample of words and features present in the combined Binder and Lancaster databases. The structure and ordering of the factors are therefore also partly specific to those words. The factors may nevertheless serve to investigate if semantics play a role in demonstrative choices, and given that the same factors and words were previously used in an analysis of English demonstratives, a comparison may show similarities and differences between the languages. The 12 factors were therefore used as predictors in two regression analyses, where they were used to predict demonstrative choices. 


\subsection{Aggregate components of demonstrative choices and principal component analyses}

Individual choices of demonstrative for words were aggregated across participants to yield a proportion of este/a (this), ese/a (this/that), and aquel/la (that) chosen for each word (see Table 2 for examples and overall proportions).

Given that the proportions always sum to $100 \%$, the distribution across the three demonstratives only has two degrees of freedom. Using principal component analysis (PCA), we therefore projected the three different demonstrative options onto the two dimensions (PC1 and PC2) on which choices were distributed. The loadings for these two components across the three demonstratives were for PC1: [0.81, $-0.34,-0.47]$, i.e., roughly corresponding to the proximal demonstrative este/a relative to the two other demonstratives combined. For PC2 it was: $[0.08,-0.74,0.66]$, i.e., roughly corresponding to the distal demonstrative aquel/a relative to the medial demonstrative ese/a, disregarding the proximal demonstrative este/a.

Table 1. Example words from the study

\begin{tabular}{|c|c|c|c|c|c|c|}
\hline \multicolumn{2}{|c|}{ Example words } & \multicolumn{3}{|c|}{ Proportion demonstrative } & \multicolumn{2}{|c|}{ Principal components } \\
\hline English & Spanish & $\begin{array}{r}\text { Este/a } \\
\text { (this) }\end{array}$ & $\begin{array}{r}\text { Ese/a } \\
\text { (this/that) }\end{array}$ & $\begin{array}{r}\text { Aquel/la } \\
\text { (that) }\end{array}$ & $P C 1$ & $P C 2$ \\
\hline ambulance & ambulancia & 0.25 & 0.45 & 0.30 & -0.145 & -0.05 \\
\hline banana & plátano & 0.58 & 0.34 & 0.08 & 0.27 & -0.08 \\
\hline diplomat & diplomático & 0.16 & 0.37 & 0.47 & -0.26 & -0.12 \\
\hline duck & pato/a & 0.24 & 0.49 & 0.27 & -0.15 & -0.10 \\
\hline family & familia & 0.55 & 0.27 & 0.18 & 0.21 & 0.02 \\
\hline home & casa & 0.48 & 0.21 & 0.31 & 0.12 & 0.15 \\
\hline night & noche & 0.43 & 0.21 & 0.36 & 0.06 & 0.18 \\
\hline toe & dedo del pie & 0.64 & 0.28 & 0.08 & 0.34 & -0.04 \\
\hline$\ldots$ & $\ldots$ & $\ldots$ & $\ldots$ & $\ldots$ & $\ldots$ & $\because$ \\
\hline $\begin{array}{l}\text { Mean }(480 \\
\text { words) }\end{array}$ & & 0.37 & 0.37 & 0.26 & & \\
\hline
\end{tabular}

\subsection{Regression analyses}

We conducted a linear regression analysis for each of the two principal components (PC1 and PC2) with PC scores for each word as dependent variable and estimated factor scores for the 12 factors as independent variables. This allowed us to determine which (if any) semantic factors could be used to predict the distribution of demonstrative 
choices across the two PC dimensions. Results were corrected for multiple comparisons using a Bonferroni correction.

\section{Results}

The overall proportion of the three demonstratives can be seen from table 1 along with distributions for example words.

\subsection{Principal Component 1}

The first linear regression model with semantic factors as independent variables and PC1 as dependent variable was highly significant (Adjusted R-squared: 0.584), indicating that the semantic factors explained variability in the choice between the proximal demonstrative este/a and the two other demonstratives (i.e., medial ese/a and distal aquel/la).

Out of the 12 semantic factors, 10 significantly contributed to the model $(\mathrm{p}<0.05$, Bonferroni corrected, see figure 1): Valence $(\mathrm{t}(459)=-9.1, \mathrm{p}<0.0001)$, Loudness $(\mathrm{t}(459)=-11.5, \mathrm{p}<0.0001)$, Human $(\mathrm{t}(459)=-8.4, \mathrm{p}<0.0001)$, Taste/Smell $(\mathrm{t}(459)=6.0$, $\mathrm{p}<0.001)$, Motion $(\mathrm{t}(459)=-4.4, \mathrm{p}<0.0002)$, Manipulability $(\mathrm{t}(459)=10.6, \mathrm{p}<0.0001)$, Scene $(\mathrm{t}(459)=-4.9, \mathrm{p}<0.0001)$, Time $(\mathrm{t}(459)=4.5, \mathrm{p}<0.0001)$, Arousal $(\mathrm{t}(459)=-4.4$, $\mathrm{p}<0.0002)$, and Self $(\mathrm{t}(459)=11.6, \mathrm{p}<0.0001)$. The factors Vision and Torso/Legs were non-significant $(\mathrm{p}>0.05)$. Positive $\mathrm{t}$-values indicate that the factor contributes positively to PC1 (i.e., elicits the proximal demonstrative este/a more often), whereas negative coefficients and t-values indicate a negative contribution to PC1 (i.e., elicits the medial ese/a or distal demonstrative aquel/la more often).

\subsection{Principal Component 2}

The 2nd linear regression model with semantic factors as independent variables and PC2 as dependent variable was also highly significant (Adjusted R-squared: 0.22), indicating that the semantic factors explained variability in the choice between the distal demonstrative aquel/la and the medial demonstrative ese/a.

Out of the 12 semantic factors, 5 significantly contributed to the model $(\mathrm{p}<0.05$, Bonferroni corrected, see figure 1): Vision $(\mathrm{t}(459)=-3.9, \mathrm{p}<0.0001)$, Taste/Smell $(\mathrm{t}(459)=-2.9, \mathrm{p}<0.05)$, Scene $(\mathrm{t}(459)=5.6, \mathrm{p}<0.0001)$, Time $(\mathrm{t}(459)=6.8, \mathrm{p}<0.0001)$, Torso/Legs $(\mathrm{t}(459)=3.2, \mathrm{p}<0.05)$. The remaining factors were non-significant $(\mathrm{p}>0.05)$ 
when correcting for multiple comparisons. Positive t-values indicate that the factor contributes positively to PC2 (i.e., elicits the distal demonstrative aquel/la more often), whereas negative coefficients and t-values indicate a negative contribution to PC2 (i.e., elicits the medial demonstrative ese/a more often).

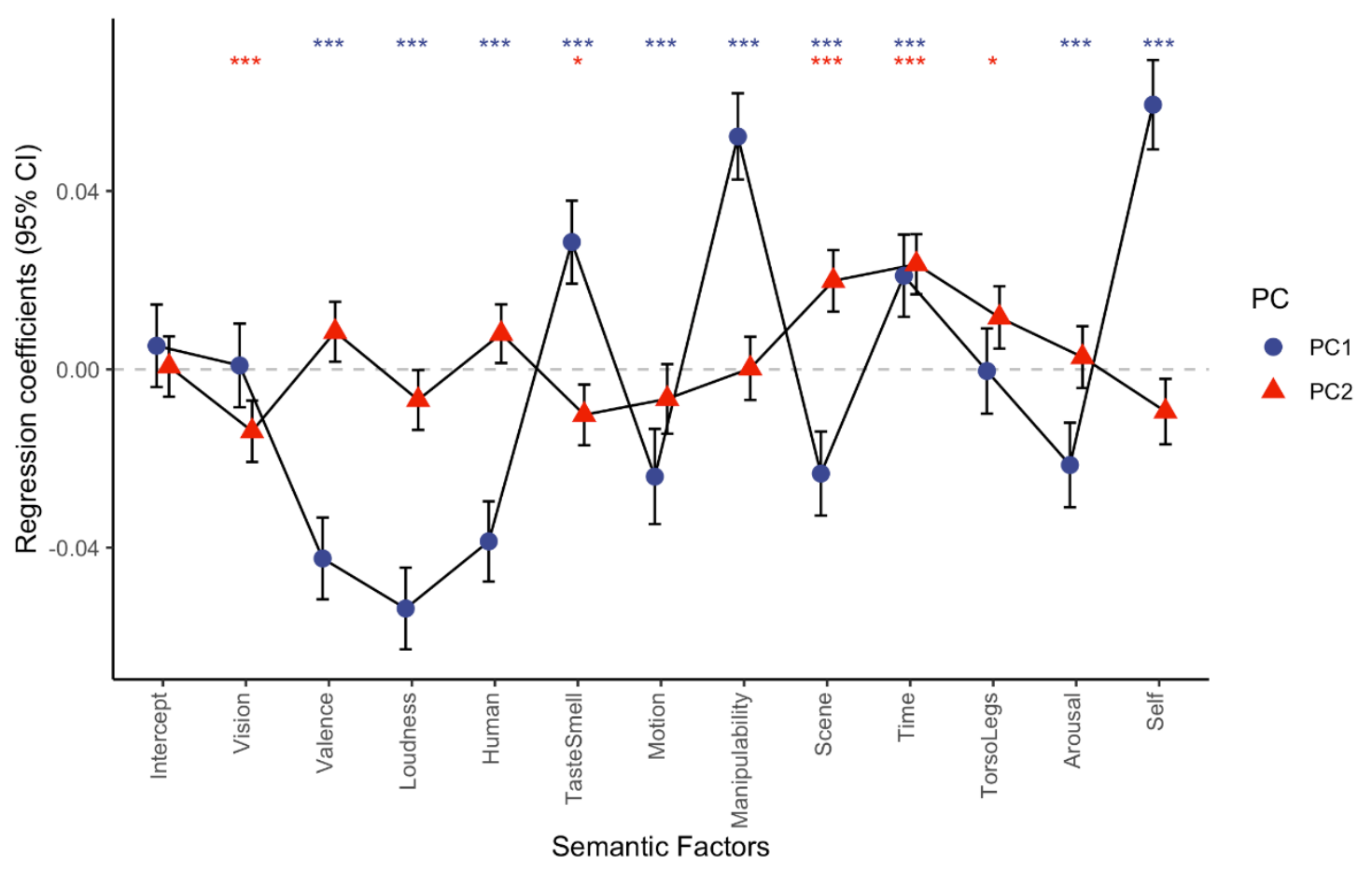

Figure 1. Regression coefficients (with 95\% confidence intervals) for the two regression analyses using semantic factors to predict percentage demonstrative choices for words. Factor analysis on a combination of 76 Binder and Lancaster semantic features resulted in 12 factors, depicted on the x-axis. Factors are labelled according to Rocca \& Wallentin (2020). Demonstrative choice of este/a (this), ese/a (this/that) and aquel/la (that) were condensed to two principal components, PC1 (blue circle) corresponds to the choice of este/a (this) vs the two non-proximal demonstratives; PC2 (red tringles) corresponds to ese/a (this/that) vs. aquel/la (that). A significant positive coefficient for PC1 means that words with a high score on a sematic factor are more likely to elicit the proximal este/a, whereas a negative coefficient means that a factor tends to elicit one of the two non-proximal demonstratives more often indiscriminately. A positive coefficient for PC2 means that a word with a high score on a semantic factor is more likely to elicit the distal $a q u e l / l a$, whereas a negative coefficient on PC2 means that a factor is more likely to elicit the medial ese/a. *:p<0.05, **: $\mathrm{p}<0.01$, ***: $\mathrm{p}<0.001$, Bonferroni corrected. 

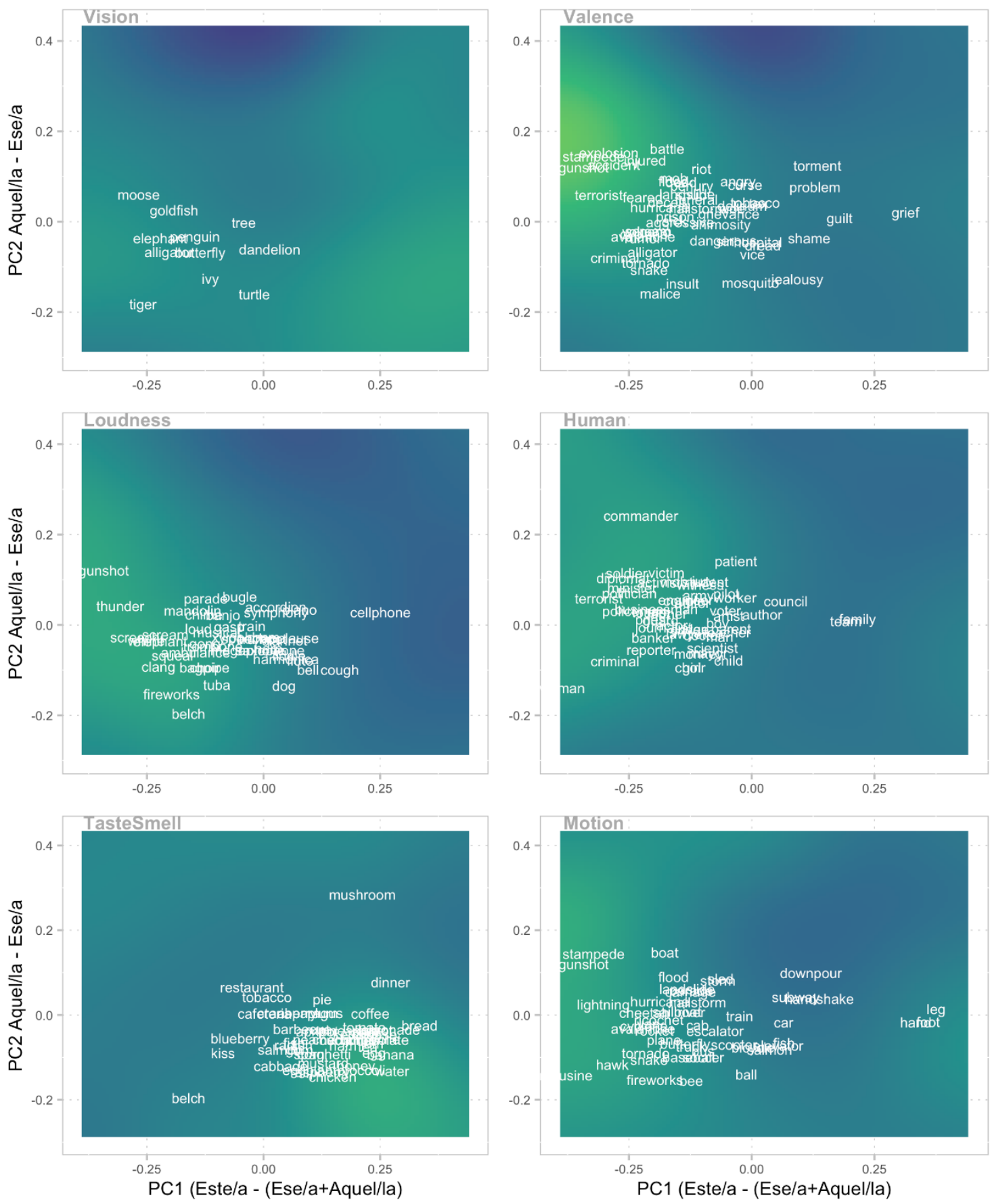

Figure 2. Each plot shows how demonstrative choices are distributed for semantic factors 1-6 (based on 76 Binder and Lancaster features): Vision, Valence, Loudness, Human, Taste/Smell, Motion. The X-axis represents principal component 1 for demonstrative choices: A positive number means that participants more often use este/a (this) than any of the other two demonstratives for words that score high on a particular semantic factor. The y-axis displays principal component 2: The difference between aquel/la (that) and ese/a (this/that). A positive number means that aquel/la (that) is chosen more often for words related to this factor. We used multilevel B-splines (Lee, et al., 1997) to interpolate the distribution of each semantic factor in 2D demonstrative space (surface plot). Yellow colors indicate a higher frequency of use for the semantic factor. The plots also include high-scoring words on each semantic factor (cutoff 1.66 standard deviations above the mean) for illustration. (Spanish version in Appendix A) 

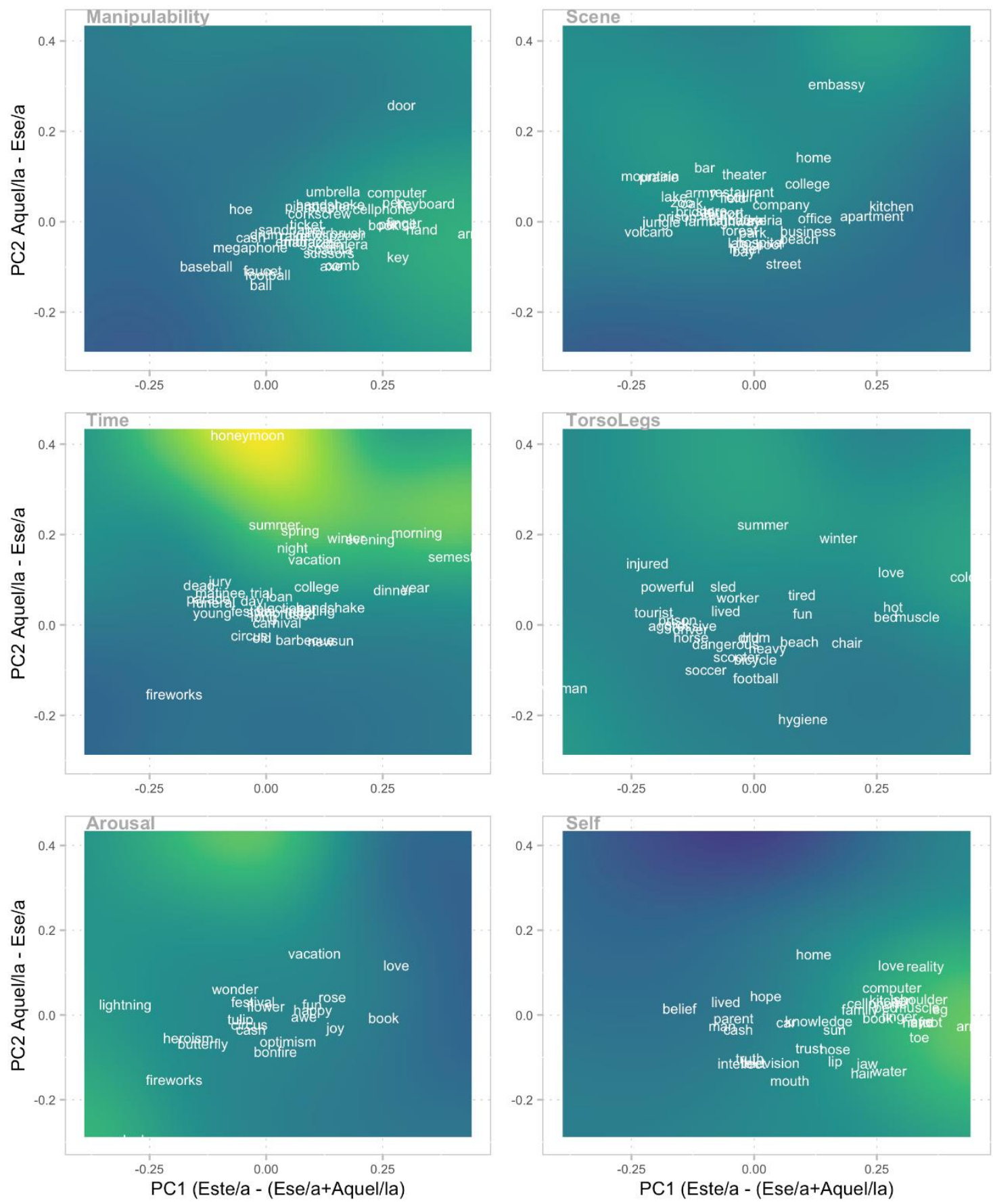

Figure 3. Each plot shows how demonstrative choices are distributed for semantic factors 7-12 (based on 76 Binder and Lancaster features): Manipulability, Scene, Time, Torso/Legs, Arousal, Self. Yellow colors indicate a higher frequency of use for the semantic factor. The xaxis represents principal component 1 for the demonstrative choices: A positive number means that participants more often use este/a (this) than any of the other two demonstratives for words that score high on a particular semantic factor. The y-axis represents principal component 2: The difference between aquel/la (that) and ese/a (this(that). A positive number means that aquel/la (that) is chosen more often for words related to this factor. We used multilevel Bsplines (Lee, et al., 1997) to interpolate the distribution of each semantic factor in 2D demonstrative space (surface plot). The plots also include high-scoring words on each semantic factor (cutoff 1.66 standard deviations above the mean) for illustration. (Spanish version in Appendix A) 


\section{Discussion}

In the present study, we adapted the DCT to Spanish to assess the influence of semantic features of the referent on speakers' choices for demonstrative forms in a three-term demonstrative system (este/ese/aquel: this/this-that/that in English), when no contextual cue is provided. Our aim was twofold. First, we aimed at ascertaining whether results obtained with two-terms demonstrative system replicate in three-term demonstrative system, that is, whether the same semantic dimensions influence speakers' preferences for proximal vs. non-proximal demonstrative forms when a language does not present a dyadic demonstrative system. Second, we aimed to assess whether the contrast between non-proximal (i.e., medial and distal) forms can also be used for semantic distinctions, that is, to assess whether particular semantic features of the referent explain speakers' choices of medial vs. distal forms, or whether the distinction between medial and distal forms is only relevant in pragmatic contexts.

Concerning the first question, our results replicate the findings from a previous DCT study with English, showing that a range of semantic factors consistently influences demonstrative choice when no context is provided (Rocca \& Wallentin 2020). The same 10 semantic factors (including Manipulability, Valence and Self) that predicted the distribution of proximal and distal demonstrative choices in English also predicted the choice of proximal (este/a) vs non-proximal (ese/a - aquel/la) demonstratives in Spanish (principal component 1 [PC1]; see Figure 1).

Concerning the second question, we outlined two potential hypotheses. Hypothesis A stated that, in the absence of any context, the three-system demonstrative system might collapse into a two-term (proximal/non-proximal) demonstrative system organized along a self/non-self dichotomy, where medial forms do not have functional/semantic specificity. Hypothesis B, on the other hand, stated that medial and distal forms retain some semantic specificity with respect to each other, and, consequently, that some semantic factor would explain speakers' choice for one form rather than the other.

Our results speak against hypothesis A. If the three-term system was reduced to a two-term system, one could either expect the use of medial or distal form to be drastically reduced (which was not the case, as it can be seen from Table 1) or that speakers would use the medial and the distal term more or less interchangeably, and therefore randomly. In this scenario, semantic factors should not be consistently related 
to participants' choices for medial (ese/a) versus distal (aquel/la) forms. However, we do detect a relationship between particular semantic dimensions of the referent and the speakers' tendency to choose medial versus distal forms. In fact, principal component 2 [PC2], which modelled the difference in use between the medial ese/a and the distal aquel/la, was significantly correlated with five different semantic factors (see Figure 1). This lends support to hypothesis B, which stated that, in the absence of spatial information, the dichotomy between the two non-proximal forms can be used to encode specific semantic distinctions.

An especially prominent example of such a semantic factor is Time (see Figure 1 and 3). As can be seen from Figure 3 (row 2, column 1), words related to Time caused a significant increase in the frequency of the distal form aquel/la compared to the medial form ese/a. Participants tended to choose 'aquella luna de miel' instead of 'esa luna de miel' (that honeymoon) and 'aquel verano' instead of 'ese verano' (that summer). Similar results have been found for other languages, such as Estonian, a two-terms system with the forms see (this-that) and too (that) where the distal term too (that) has been found to be especially used for fixed expressions related to the same semantic dimension of Time (Pajusalu, 2006). Conversely, a high score on the factor Vision increased participants' likelihood to use the medial demonstrative ese/a relative to the distal demonstrative aquel/la. As can be seen from Figure 2, high scorers on this factor include animate beings, such as animals and plants. Participants tended to use 'ese tigre' instead of 'aquel tigre' (that tiger) and 'esa tortuga' was more frequent than 'aquella tortuga' (that turtle). Animacy has previously been found to influence choice of demonstratives (Rocca et al. 2019a), especially in interaction with harmfulness. Isolating the individual contribution of Animacy (for which no explicit factor exists in this analysis) vs. Vision requires more fine-grained analyses. Overall, our results thus suggest that, while in Spanish the proximal/non-proximal distinction is explained by the same semantic factors detected for the proximal/distal contrast in English (with the same 10 semantic factors contributing to demonstrative choice), in Spanish the medial factor also retains semantic specificity.

Our observations that ese/a (this-that) and aquel/la (that) may be used to code for semantic distinctions are in line with observations from Argentinian Spanish, where patterns of usage of medial versus distal terms are also consistently driven by nonspatial dimensions (here, aquel/la is used only in formal contexts). Another parallel is Majorcan Catalan - where the medial term aqueix/a has dropped out of the system when 
conveying physical distance, but can be used to mark social distance (Pérez-Saldanya, 2015; Todisco et al., 2021). A general description of the relationship between expressiveness and complexity (i.e., number of forms) of demonstrative systems goes beyond the scope of the present studies, but it is an extremely interesting research avenue. On the one hand, the examples of Spanish and Argentinian may indeed suggest that maintaining a three-term (more complex) system may allow more refined referencing in relevant situations, also outside physical space. On the other hand, in languages with "simpler", two-term demonstrative referencing systems, modulations of the dyadic system (e.g., by combining demonstrative particles and adverbs) may be used to carve more fine-grained distinctions and therefore retain high expressivity. Italian, for instance, presents a two-term demonstrative system (questo/quello), but speakers often use these combinations of a demonstrative and a locative adverb for more fine-grained referencing (e.g., questo qui, 'this here', Jungbluth \& Da Milano, 2015). Studies on the relationships and trade-offs between lexical complexity of demonstrative systems, affordances for pragmatic modulations, and expressivity would, in our opinion, be a highly valuable contribution to the literature.

To conclude, showing that semantic patterns psychologically or quantitatively replicate not only in languages with two-term demonstrative systems (i.e., Italian, Danish in Rocca et al., 2019a; English in Rocca \& Wallentin, 2020), but also in languages with more than two demonstrative terms provides a strong argument in favour of these mechanisms capturing some fundamental aspect of the relation between human cognition, semantics and linguistic forms. Overall, these results are in line with the idea suggested by Rocca and Wallentin (2020), that the frame of reference for demonstrative use - at least in absence of an explicit interlocutor - instantiates the speaker as deictic centre, and projects away from this centre in both physical and psychological dimensions. When non-spatial semantic entities are referred to, the coordinate system is structured along psychological (e.g., familiarity, affect), semantic and imaginative dimensions, rather than spatial ones (Coventry et al., 2014; Stukenbrock, 2014; Rocca \& Wallentin, 2020).

A number of points remain open to investigation. First, our results lend support to the hypothesis that semantics systematically influences the choice of specific demonstrative forms when no context is provided. So far, however, effects of semantic dimensions on demonstrative choice have been described for a few languages, and some that are arguably not so dissimilar from a cultural and typological standpoint. A more 
extensive overview of the extent to which the detected dynamics generalize across languages is warranted. Conducting the DCT on a wider range of languages (using comparable words and feature sets), ideally covering a broader typological and cultural spectrum, would pave the way towards a deeper understanding of the cognitive mechanisms underlying the complex functioning of deictic reference and its relationship with cultural differences, given that the semantic dimensions will be the same for each language under analysis, independently of the context of utterance.

Investigating how this semantic space interacts with physical and conversational space is also a crucial avenue for future research, together with a more in-depth analysis of collocation patterns found in corpora of spoken and written language. This may shed light on whether the same semantic distinctions observed through the DCT can be observed in 'naturalistic' contexts. The analysis of corpora may replicate the effects found in our studies, but also enrich the picture with knowledge of usage patterns which are more conventional (e.g., common colocations) than purely driven by semantics.

Finally, our understanding of the topology of demonstrative systems with more than two terms and their relation to dyadic system could be significantly improved by expanding the DCT to languages, such as Catalan, which present a reduction from three to two terms.

\section{Conclusions}

In the present study, we used the Demonstrative Choice Task (DCT) to investigate the relationship between demonstrative use and semantics in Spanish, a language with three demonstrative terms. We have provided evidence that demonstrative choice is influenced by a number of semantic dimensions (spatial, bodily and emotional features). The contrast between proximal and distal forms is driven by the same dimensions which have been previously found to influence demonstrative choice in English. Semantic effects are thus replicable across languages, which hints at some degree of invariance in cognitive mechanisms underlying demonstrative reference. Additional semantic factors consistently influenced speakers' preferences for medial and distal forms, which suggests that the medial/distal distinction can be recruited to express finer-grained semantic contrasts. 


\section{References}

Binder, J. R., Conant, L. L., Humphries, C. J., Fernandino, L., Simons, S. B., Aguilar, M., \& Desai, R. H. (2016). Toward a Brain-based Componential Semantic Representation. Cognitive Neuropsychology, 33(3-4),130-174.

Bühler, K. (1934/2011). Theory of Language - The Representational Function of Language [Sprachtheorie]. Amsterdam: John Benjamins Publishing.

Bocale, P., \& Cologna, D. B. (2020). The Expression of Epistemic Uncertainty Thought the Use of Distal Demonstratives in Russian and Chinese: A Cognitive Analysis of Corpus Data. International Journal of Linguistics, 12(2), 57-82.

doi:10.5296/ijl.v12i2.16438

Caldano, M., \& Coventry, K. R. (2019). Spatial Demonstratives and Perceptual Space:

To Reach or not to Reach? Cognition, 191, 103989.

Chen, R. (1990). English Demonstratives: A Case of Semantic Expansion. Language Sciences, 12, 139-153.

Cooperrider, K. (2016). The Co-Organization of Demonstratives and Pointing Gestures. Discourse Processes, 53, 632-656.

Coventry, K. R., Griffiths, D., \& Hamilton, C. J. (2014). Spatial Demonstratives and Perceptual Space: Describing and Remembering Object Location. Cognitive Psychology, 69, 46-70.

Coventry, K. R., Valdés, B., Castillo, A., \& Guijarro-Fuentes, P. (2008). Language Within your Reach: Near-far Perceptual Space and Spatial Demonstratives. Cognition, 108, 889-895.

Di Pellegrino, G., \& Làdavas, E. (2015). Peripersonal Space in the Brain. Neuropsychologia, 66, 126-133.

Diessel, H. (1999). Demonstratives: Form, Function and Grammaticalization. Amsterdam: John Benjamins Publishing.

Diessel, H. (2005). Distance Contrasts in Demonstratives. In M., Haspelmath, M. S., Dryer, D., Gil, \& B., Comrie (eds.). World Atlas of Language Structures, (pp. 170-173). Oxford: Oxford University Press.

Diessel, H. (2013). Where Does Language Come From? Some Reflections on the Role of Deictic Gesture and Demonstratives in the Evolution of Language. Language and Cognition, 5, 239-249. https://doi.org/10.1515/langcog-2013-0017 
Diessel, H. (2014). Demonstratives, Frames of Reference, and Semantic Universals of Space. Language and Linguistics Compass, 8/3, 116-132.

Diessel, H. \& Coventry, K. R. (2020). Demonstratives in Spatial Language and Social Interaction: An Interdisciplinary Review. Frontiers of Psychology, 11: 555265. doi: 10.3389/fpsyg.2020.555265

Dragulescu, A. \& Arendt, C. (2020). xlsx. https://CRAN.R-project.org/package=xlsx Dufter, A. (2015). Semantics. In K., Jungbluth, \& F. Da Milano, (eds.) Manual of Deixis in Romance Languages (pp. 359-380). Berlin/Boston: Walter de Gruyter. Finley, A., Banerjee, S., Hjelle, Ø., \& Bivand, R. (2017). MBA: Multilevel B-Spline Approximation, https://CRAN.R-project.org/package=MBA

Fricke, E. (2014). Deixis, Gesture, and Embodiment from a Linguistic Point of View. In C. Müller, et al. (Eds.), Body, Language, Communication (pp. 1803-1823). De Gruyter. https://doi.org/10.1515/9783110302028.1803

Gudde, H. B., Griffiths, D., \& Coventry, K. R. (2018). The (Spatial) Memory Game: Testing the Relationship between Spatial Language, Object Knowledge, and Spatial Cognition. Journal of Visualized Experiments, 132. Doi: 10.3791/56495

Horn, J. L. (1965). A Rationale and Test for the Number of Factors in Factor Analysis. Psychometrika, 30, 179-185.

Hottenroth, P. (1982). Locative in Spanish, in Here and There: Cross-linguistics studies on deixis and demonstratives. Amsterdam: John Benjamin Publishing.

Hunley, S. B., \& Lourenco, S. F. (2018). What is Peripersonal Space? An Examination of Unresolved Empirical Issues and Emerging Findings. Wiley Interdisciplinary Reviews, Cognitive Science, 9(6). DOI: 10.1002/wcs.1472 Iverson, J. M., Tencer, H. L., Lany, J., \& Goldin-Meadow, S. (2000). The Relation between Gesture and Speech in Congenitally Blind and Sighted Language-Learners. Journal of Nonverbal Behavior, 24(2), 105-130.

Jungbluth, K. (2003). Deictics in the Conversational Dyad: Findings in Spanish and some Cross-linguistic Outlines. In F. Lenz (Ed.), Deictic Conceptualisation of Space, Time and Person (pp. 13-40). Amsterdam: John Benjamins Publishing. Jungbluth, K., \& Da Milano, F. (2015). Manual of Deixis in Romance Languages. Berlin/Boston: Walter de Gruyter.

Kemmerer, D. (2006). The Semantics of Space: Integrating Linguistic Typology and Cognitive Neuroscience. Neuropsychologia, 44, 1607-1621. 
Kita, S. (2003). Pointing: Where Language Culture, and Cognition Meet. Mahwah, NJ, US: Lawrence Erlbaum Associates Publishers.

Küntay, A. C., \& Özyürek, A. (2002). Joint attention and the development of the use of demonstratives in Turkish. Proceedings of the 26th Annual Boston University

Conference on Language Development. Somerville, MA: Cascadilla Press. 26, 336-347. Lee, S., Wolberg, G., \& Shin, S. Y. (1997). Scattered Data Interpolation with Multilevel B-splines. IEEE Transactions on Visualization and Computer Graphics, 3, 228-244. Leech, G., Rayson, P., \& Wilson, A. (2014). Word Frequencies in Written and Spoken English: Based on the British National Corpus. London: Routledge.

Levinson, S. (2018). Introduction: Patterns in Diversity. In S., Levinson, S., Cutfield, M., Dunn, N., Enfield, \& Meira, S. (Eds.) (pp. 1-42). Demonstratives in CrossLinguistic Perspective (Language Culture and Cognition). Cambridge: Cambridge University Press. doi:10.1017/9781108333818

Lin Lin. (2013). A semantic study of German and Chinese demonstratives (Doctoral dissertation, University of Los Angeles, California. Retrieved from: https://escholarship.org/uc/item/9v40c1w2. Lynott, D., Connell, L., Brysbaert, M., Brand, J., \& Carney, J. (2020). The Lancaster Sensorimotor Norms: Multidimensional Measures of Perceptual and Action Strength for 40,000 English Words. Behavior Research Methods, 52, 1271-1291. https://doi.org/10.3758/s13428-019-01316-z Pajusalu, R. (2006). Death of a demonstrative: person and time. The case of Estonian too. Linguistica Uralica 42(4). 241-253.

Peeters, D., Krahmer, E., \& Maes, A. A. (2020). A Conceptual Framework for the Study of Demonstrative Reference, PsyArXiv. https://doi.org/10.31234/osf.io/ntydq Peeters, D., Hagoort, P., \& Özyürek A. (2015). Electrophysiological Evidence for the Role of Shared Space in Online Comprehension of Spatial Demonstratives. Cognition, 136, 64-84. https://doi.org/10.1016/j.cognition.2014.10.010 Pérez-Saldanya, M. (2015). Paradigms as Triggers of Semantic Change: Demonstrative Adverbs in Catalan and Spanish. Catalan Journal of Linguistics, 14, 113-135. R Core Team (2020). R: A language and environment for statistical computing. R Foundation for Statistical Computing, Vienna, Austria. URL https://www.Rproject.org/. 
Revelle, W. (2017). psych: Procedures for Personality and Psychological Research, Northwestern University, Evanston, Illinois, USA, https://CRAN.Rproject.org/package $=$ psych

Revelle, W. (2019). psych: Procedures for Psychological, Psychometric, and Personality Research. In: Northwestern University.

Rocca, R., \& Wallentin, M. (2020). Demonstrative Reference and Semantic Space: A Large-Scale Demonstrative Choice Task Study. Frontiers in Psychology, 11.

Rocca, R., Tylén, K., \& Wallentin, M. (2019a). This Shoe, That Tiger: Semantic Properties Reflecting Manual Affordances of the Referent Modulate Demonstrative Use. PloS One, 14, e0210333.

Rocca, R., Wallentin, M., Vesper, C., \& Tylén, K. (2018). This and That back in Context: Grounding Demonstrative Reference in Manual and Social Affordances. In Proceedings of The 40th Annual Meeting Of The Cognitive Science Society. Madison, Wisconsin.

Rocca, R., Wallentin, M., Vesper, C., \& Tylén, K. (2019b). This is for You: Social Modulations of Proximal vs. Distal Space in Collaborative Interaction. Scientific Reports, 9, 14967.

RStudio Team. (2016). RStudio: Integrated Development for R. RStudio, Inc.,Boston, MA URL http://www.rstudio.com/).

Strauss, S. (2002). This, That, and It in Spoken American English: a Demonstrative System of Gradient Focus. Language Sciences, 24, 131-152.

Stukenbrock, A. (2014). Pointing to an 'Empty' Space: Deixis am Phantasma in Faceto-face Interaction. Journal of Pragmatics, 74, 70-93.

Stukenbrock, A. (2015). Intercorporeal Phantasms: Kinesthetic Alignment with Imagined Bodies in Self-Defense Trainings. International and Linguistic Structures, 58, $1-23$.

Talmy, L. (1983). How Language Structures Space. In Spatial Orientation (pp. 225282). Springer, Boston, MA.

Talmy, L. (1988). The Relation of Grammar to Cognition. In B. Rudska-Ostyn (Ed.), Topics in Cognitive Linguistics (pp. 165-206). Amsterdam: John Benjamins.

Talmy, L. (2018). The Targeting System of Language. MIT Press. https://doi.org/10.1515/cog-2018-0061 
Todisco, E., Guijarro-Fuentes, P., Collier, J., \& Coventry, K. R. (2020). The Temporal Dynamics of Deictic Communication. First Language, 41/2, 154-178.

https://doi.org/10.1177/0142723720936789

Todisco, E., Guijarro-Fuentes, P., \& Coventry, K. R. (2021). Analogical Levelling in the Majorcan Catalan Demonstrative System. Probus International Journal of Romance Linguistics. DOI: https://doi.org/10.1515/probus-2021-0001

Todisco, E., Guijarro-Fuentes, P., Gudde, H. \& Coventry, K. R. (in preparation). Deixis, Bilingualism and Hearer Position Effects in Spanish and Majorcan Catalan systems of demonstratives.

Wilkins, D. P. (1999). Demonstrative Questionnaire: "THIS" and "THAT" in comparative perspective. In David P. Wilkins, ed., "Manual” for the 1999 Field Season, (pp.1-24). Nijmegen: MPI for Psycholinguistics.

Wickham (2020). reshape2. https://cran.r-project.org/web/packages/reshape2/index.html Wickham et al., (2019). Welcome to the tidyverse. Journal of Open Source Software, 4(43), 1686, https://doi.org/10.21105/joss.01686

Wickham, Seidel, D. RStudio. (2020). scales. https://cran.rproject.org/web/packages/scales/index.html

Wilke, C.O. (2020). cowplot. https://cran.rproject.org/web/packages/cowplot/index.html

Xiao, N., Li, M. (2018). ggsci-package. https://cran.rproject.org/web/packages/ggsci/vignettes/ggsci.html 


\section{Figure Legends}

\section{Figure 1}

Regression coefficients (with $95 \%$ confidence intervals) for the two regression analyses using semantic factors to predict percentage demonstrative choices for words. Factor analysis on a combination of 76 Binder and Lancaster semantic features resulted in 12 factors, depicted on the x-axis. Factors are labelled according to Rocca \& Wallentin (2020). Demonstrative choice of este/a (this), ese/a (this/that) and aquel/la (that) were condensed to two principal components, PC1 (blue circle) corresponds to the choice of este/a (this) vs the two non-proximal demonstratives; PC2 (red tringles) corresponds to ese/a (this/that) vs. aquel/la (that). A significant positive coefficient for PC1 means that words with a high score on a sematic factor are more likely to elicit the proximal este/a, whereas a negative coefficient means that a factor tends to elicit one of the two non-proximal demonstratives more often indiscriminately. A positive coefficient for PC2 means that a word with a high score on a semantic factor is more likely to elicit the distal aquel/la, whereas a negative coefficient on PC2 means that a factor is more likely to elicit the medial ese/a. *:p<0.05, **: $\mathrm{p}<0.01, * * *: \mathrm{p}<0.001$, Bonferroni corrected.

\section{Figure 2}

Each plot shows how demonstrative choices are distributed for semantic factors 1-6 (based on 76 Binder and Lancaster features): Vision, Valence, Loudness, Human, Taste/Smell, Motion. The X-axis represents principal component 1 for demonstrative choices: A positive number means that participants more often use este/a (this) than any of the other two demonstratives for words that score high on a particular semantic factor. The y-axis displays principal component 2: The difference between aquel/la (that) and ese/a (this/that). A positive number means that aquel/la (that) is chosen more often for words related to this factor. We used multilevel B-splines (Lee, et al., 1997) to interpolate the distribution of each semantic factor in 2D demonstrative space (surface plot). Yellow colors indicate a higher frequency of use for the semantic factor. The plots also include high-scoring words on each semantic factor (cutoff 1.66 standard deviations above the mean) for illustration. (Spanish version in Appendix A)

\section{Figure 3}

Each plot shows how demonstrative choices are distributed for semantic factors 7-12 (based on 76 Binder and Lancaster features): Manipulability, Scene, Time, Torso/Legs, Arousal, Self. Yellow colors indicate a higher frequency of use for the semantic factor. The X-axis represents principal component 1 for the deomonstrative choices: A positive number means that participants more often use este/a (this) than any of the other two demonstratives for words that score high on a particular semantic factor. The $y$-axis represents principal component 2: The difference between aquel/la (that) and ese/a (this(that). A positive number means that aquel/la (that) is chosen more often for words related to this factor. We used multilevel B-splines (Lee, et al., 1997) to interpolate the distribution of each semantic factor in 2D demonstrative space (surface plot). The plots also include high-scoring words on each semantic factor (cutoff 1.66 standard deviations above the mean) for illustration. (Spanish version in Appendix A) 
Appendix A: (Spanish version of Figure 2)
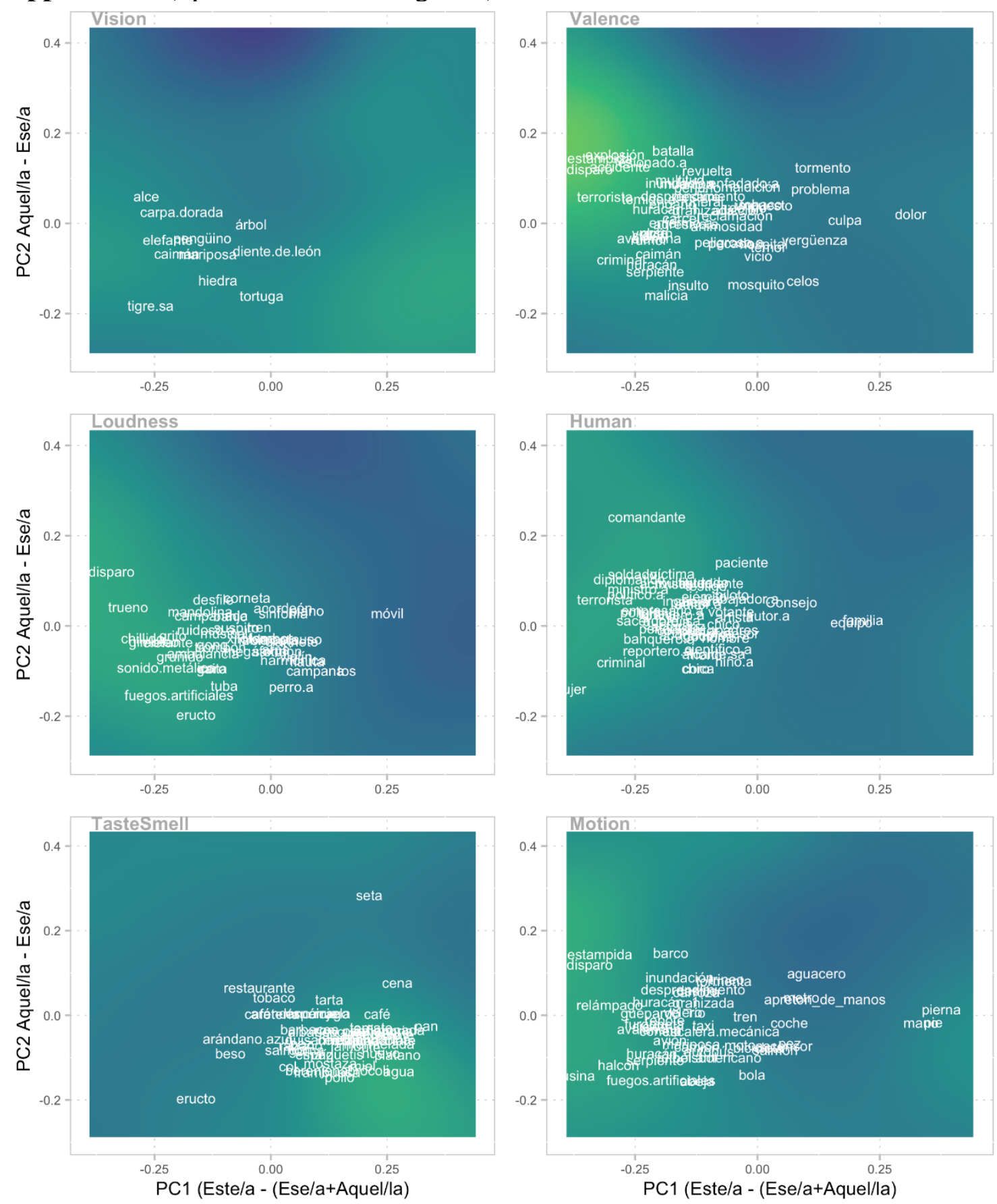
Appendix A: (Spanish version of Figure 3)
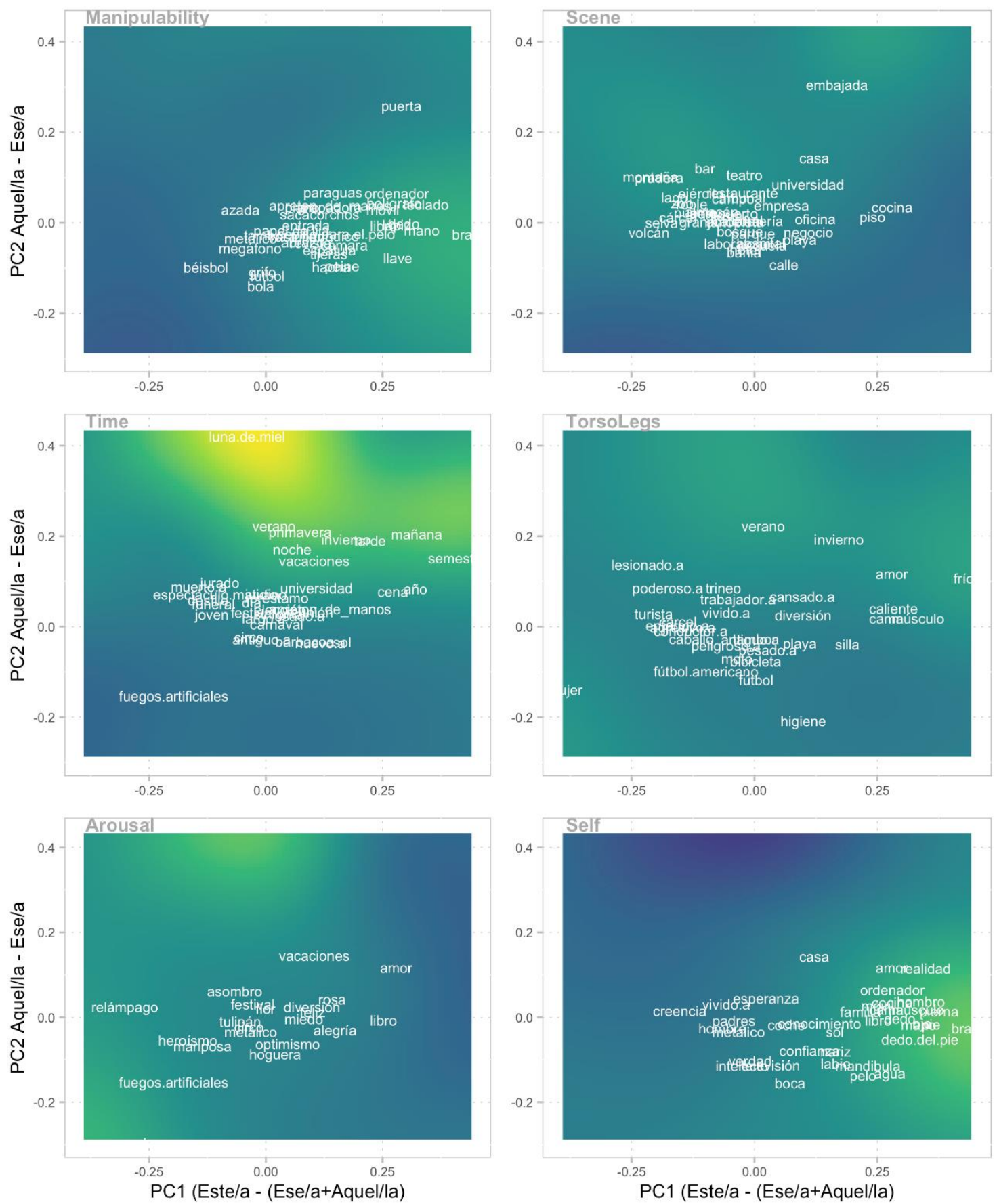
Appendix B: The figures represent the experimental setting in both laptop and mobile versions.

\section{Laptop version:}
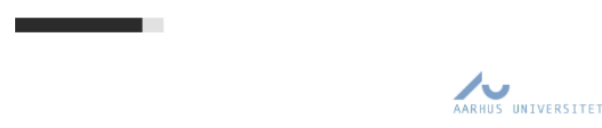

$O$ aquel/tis

o este/a

Mobile version:

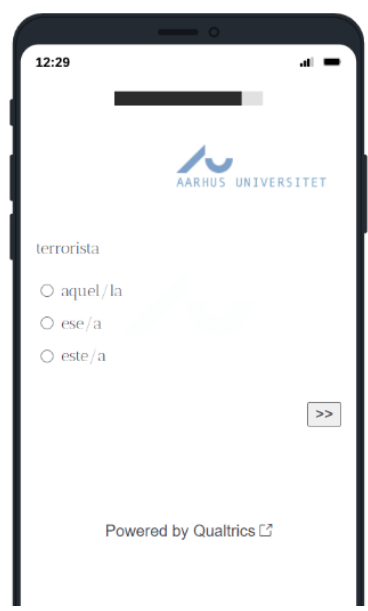


Appendix C: here we report the words used in the DCT both in English and Spanish

\begin{tabular}{|c|c|c|c|}
\hline Word_English & Word_Spanish & Word_English & Word_Spanish \\
\hline helped & ayudado/a & restaurant & restaurante \\
\hline advantage & ventaja & ricochet & rebote \\
\hline applause & aplauso & semester & semestre \\
\hline awe & miedo & $\sin$ & pecado \\
\hline banjo & banjo & snub & desaire \\
\hline banker & banquero/a & spring & primavera \\
\hline belief & creencia & teacher & profesor/a \\
\hline bicycle & bicicleta & thunder & trueno \\
\hline blue & azul & tiger & tigre/sa \\
\hline bread & pan & tomato & tomate \\
\hline bridge & puente & truce & tregua \\
\hline cabinet & gabinete & trumpet & trompeta \\
\hline cheese & queso & volcano & volcán \\
\hline circus & circo & white & blanco/a \\
\hline clever & inteligente & whole & totalidad \\
\hline clue & pista & xylophone & xilófono \\
\hline cough & tos & aggressive & agresivo/a \\
\hline council & Consejo & angry & enfadado/a \\
\hline cucumber & pepino & barbecue & barbacoa \\
\hline dark & oscuro/a & bell & campana \\
\hline day & día & book & libro \\
\hline driver & conductor/a & business & negocio \\
\hline farmer & granjero/a & $c a b$ & $\operatorname{taxi}$ \\
\hline faucet & grifo & cabbage & col \\
\hline feared & temido/a & cafeteria & cafetería \\
\hline field & campo & carrot & zanahoria \\
\hline forest & bosque & chair & silla \\
\hline glass & vaso & church & iglesia \\
\hline hand & mano & clang & sonido metálico \\
\hline hoe & azada & clarinet & clarinete \\
\hline honeymoon & luna de miel & coffee & café \\
\hline hope & esperanza & dead & muerto/a \\
\hline hospital & hospital & doctor & doctor/a \\
\hline hotel & hotel & eggplant & berenjena \\
\hline ice & hielo & embrace & abrazo \\
\hline lake & lago & envy & envidia \\
\hline mushroom & seta & etiquette & etiqueta \\
\hline old & antiguo/a & excuse & excusa \\
\hline park & parque & farm & granja \\
\hline patient & paciente & finger & dedo \\
\hline piano & piano & fireworks & fuegos artificiales \\
\hline pig & cerdo/a & football & fútbol \\
\hline plum & ciruela & gong & gong \\
\hline reporter & reportero/a & guard & guardia \\
\hline
\end{tabular}


DCT in Spanish spatial demonstratives Todisco, Rocca \& Wallentin (2021)

\begin{tabular}{|c|c|c|c|}
\hline guilt & culpa & dusty & polvoriento/a \\
\hline hair & pelo & election & elección \\
\hline home & casa & escalator & escalera mecánica \\
\hline jealousy & celos & evening & tarde \\
\hline lawyer & abogado/a & expensive & caro/a \\
\hline magazine & revista & friendly & simpático/a \\
\hline moose & alce & fun & diversión \\
\hline moral & moral & garden & jardín \\
\hline musical & musical & green & verde \\
\hline new & nuevo/a & grief & dolor \\
\hline paradox & paradoja & grievance & reclamación \\
\hline pen & bolígrafo & happy & feliz \\
\hline pineapple & piña & harp & arpa \\
\hline plane & avión & highway & autopista \\
\hline plea & petición & hot & caliente \\
\hline priest & sacerdote/isa & hygiene & higiene \\
\hline raspberry & frambuesa & jaw & mandíbula \\
\hline sailboat & velero & joviality & jovialidad \\
\hline saxophone & saxofón & judge & juez/a \\
\hline screech & chillido & limousine & limusina \\
\hline shame & vergüenza & loud & ruidoso/a \\
\hline tangerine & mandarina & luck & suerte \\
\hline turtle & tortuga & malice & malicia \\
\hline verb & verbo & mayor & alcalde/sa \\
\hline water & agua & megaphone & megáfono \\
\hline wealthy & rico/a & mercy & misericordia \\
\hline winter & invierno & minister & ministro/a \\
\hline witness & testigo & noun & nombre \\
\hline woman & mujer & oak & roble \\
\hline year & año & parade & desfile \\
\hline young & joven & pie & tarta \\
\hline zone & zona & policeman & policía \\
\hline activist & activista & rake & rastrillo \\
\hline ambulance & ambulancia & rocket & cohete \\
\hline avalanche & avalancha & rose & rosa \\
\hline bonfire & hoguera & salmon & salmón \\
\hline broccoli & brócoli & saw & sierra \\
\hline businessman & empresario/a & street & calle \\
\hline camel & camello/a & theme & tema \\
\hline camera & cámara & tobacco & tabaco \\
\hline cherry & cereza & toe & dedo del pie \\
\hline choir & coro & tornado & huracán \\
\hline cranberry & arándano rojo & tourist & turista \\
\hline criminal & criminal & treaty & tratado \\
\hline curse & maldición & vacation & vacaciones \\
\hline vice & vicio & sandpaper & papel de lija \\
\hline
\end{tabular}


DCT in Spanish spatial demonstratives Todisco, Rocca \& Wallentin (2021)

\begin{tabular}{|c|c|c|c|}
\hline worth & valor & scientist & científico/a \\
\hline accordion & acordeón & shoulder & hombro \\
\hline apology & disculpa & soccer & fútbol americano \\
\hline apricot & albaricoque & speech & habla \\
\hline bay & bahía & stapler & grapadora \\
\hline beer & cerveza & student & estudiante \\
\hline cathedral & catedral & submarine & submarino \\
\hline cheetah & guepardo & subway & metro \\
\hline college & universidad & theater & teatro \\
\hline corkscrew & sacacorchos & theory & teoría \\
\hline dandelion & diente de león & torment & tormento \\
\hline dangerous & peligroso/a & voter & votante \\
\hline delirium & delirio & wanted & querido/a \\
\hline dictation & dictado & window & ventana \\
\hline embassy & embajada & worker & trabajador/a \\
\hline empty & vacío/a & zoo & ZOO \\
\hline explosion & explosión & damaged & dañado/a \\
\hline fence & valla & airport & aeropuerto \\
\hline fiddle & violín & analogy & analogía \\
\hline fish & pez & arm & brazo \\
\hline flower & flor & attribute & atributo \\
\hline flute & flauta & audience & auditorio \\
\hline fountain & fuente & bus & autobús \\
\hline gasp & suspiro & car & coche \\
\hline goldfish & carpa dorada & carriage & carroza \\
\hline hall & sala & chestnut & castaña \\
\hline honey & miel & chicken & pollo \\
\hline insult & insulto & computer & ordenador \\
\hline ire & ira & corn & maíz \\
\hline jam & mermelada & court & tribunal \\
\hline $1 \mathrm{ab}$ & laboratorio & desk & escritorio \\
\hline landslide & desprendimiento & egg & huevo \\
\hline leg & pierna & eye & ojo \\
\hline $\operatorname{man}$ & hombre & festival & festival \\
\hline mandolin & mandolina & folly & locura \\
\hline matinee & espectáculo matutino & foot & pie \\
\hline patent & patente & funeral & funeral \\
\hline pea & guisante & girl & chica \\
\hline pilot & piloto & gum & goma \\
\hline plot & guion & hailstorm & granizada \\
\hline protest & protesta & ham & jamón \\
\hline reality & realidad & heavy & pesado/a \\
\hline red & rojo/a & heroism & heroísmo \\
\hline riot & revuelta & hierarchy & jerarquía \\
\hline horse & caballo & commander & comandante \\
\hline hurricane & huracán_1 & crib & cuna \\
\hline
\end{tabular}


DCT in Spanish spatial demonstratives Todisco, Rocca \& Wallentin (2021)

\begin{tabular}{|c|c|c|c|}
\hline infinity & infinito & crow & cuervo \\
\hline irony & ironía & denial & negación \\
\hline joke & broma & $\operatorname{dog}$ & perro/a \\
\hline joy & alegría & downpour & aguacero \\
\hline key & llave & dread & temor \\
\hline lived & vivido/a & drum & tambor \\
\hline majority & mayoría & duck & pato/a \\
\hline mob & multitud & editor & editor/a \\
\hline mountain & montaña & elm & olmo \\
\hline parent & padres & engineer & ingeniero/a \\
\hline power & poder & family & familia \\
\hline prairie & pradera & fate & destino \\
\hline prison & cárcel & hamster & hámster \\
\hline role & rol & hawk & halcón \\
\hline scissors & tijeras & island & isla \\
\hline shiny & brillante & jungle & selva \\
\hline small & pequeño/a & jury & jurado \\
\hline snake & serpiente & ketchup & salsa de tomate \\
\hline squeal & gruñido & kiss & beso \\
\hline stampede & estampida & kitchen & cocina \\
\hline stone & piedra & knowledge & conocimiento \\
\hline sum & suma & legality & legalidad \\
\hline summer & verano & long & largo/a \\
\hline team & equipo & lust & lujuria \\
\hline television & televisión & meeting & reunión \\
\hline train & tren & morning & mañana \\
\hline truck & camión & mosquito & mosquito \\
\hline used & usado/a & mouth & boca \\
\hline whine & gimoteo & nose & nariz \\
\hline yellow & amarillo/a & number & número \\
\hline alligator & caimán & peaceful & pacífico/a \\
\hline army & ejército & politician & político/a \\
\hline bagpipe & gaita & radish & rábano \\
\hline banana & plátano & river & río \\
\hline bar & bar & shelves & estanterías \\
\hline bed & cama & soft & suave \\
\hline blueberry & arándano azul & spaghetti & espaguetis \\
\hline boy & chico & spatula & espátula \\
\hline bribe & soborno & \begin{tabular}{|l|} 
spiritual \\
\end{tabular} & espiritual \\
\hline butterfly & mariposa & testimony & testimonio \\
\hline carnival & carnaval & tired & cansado/a \\
\hline cash & metálico & trial & juicio \\
\hline cold & frío & tulip & tulipán \\
\hline umbrella & paraguas & scream & grito \\
\hline wit & humor & sick & enfermo/a \\
\hline accident & accidente & soldier & soldado \\
\hline
\end{tabular}




\begin{tabular}{|c|c|c|c|}
\hline advice & sugerencia & sun & sol \\
\hline animosity & animosidad & sympathy & piedad \\
\hline ant & hormiga & symphony & sinfonía \\
\hline apartment & piso & table & mesa \\
\hline artist & artista & $\operatorname{tax}$ & impuesto \\
\hline author & autor/a & tea & té \\
\hline baseball & béisbol & terrorist & terrorista \\
\hline big & grande & ticket & entrada \\
\hline bird & pájaro/a & tribute & tributo \\
\hline black & negro/a & trombone & trombón \\
\hline boat & barco & trust & confianza \\
\hline bugle & corneta & tuba & tuba \\
\hline cellphone & móvil & van & furgoneta \\
\hline chime & campanada & whale & ballena \\
\hline chipmunk & ardilla & actor & actor/actriz \\
\hline chocolate & chocolate & agreement & acuerdo \\
\hline cloud & nube & asparagus & espárrago \\
\hline comb & peine & axe & hacha \\
\hline deceit & engaño & ball & bola \\
\hline elephant & elefante & battle & batalla \\
\hline era & era & beach & playa \\
\hline fee & tarifa & bee & abeja \\
\hline gunshot & disparo & belch & eructo \\
\hline handshake & apretón de manos & child & niño/a \\
\hline heredity & herencia & company & empresa \\
\hline keyboard & teclado & couple & pareja \\
\hline lemonade & limonada & cyclone & ciclón \\
\hline lonely & solitario/a & debate & debate \\
\hline love & amor & dime & $\begin{array}{l}\text { moneda de } 10 \\
\text { céntimos }\end{array}$ \\
\hline medicine & medicina & dinner & cena \\
\hline motive & motivo & diplomat & diplomático \\
\hline mouse & ratón & dolphin & delfín \\
\hline muscle & músculo & door & puerta \\
\hline mustard & mostaza & elevator & ascensor \\
\hline newspaper & periódico & fallacy & falacia \\
\hline night & noche & famous & famoso/a \\
\hline oration & discurso & feather & pluma \\
\hline peace & paz & flood & inundación \\
\hline pumpkin & calabaza & gratitude & gratitud \\
\hline rumo & rumor & hairbrush & cepillo para el pelo \\
\hline satire & sátira & harmonica & harmónica \\
\hline school & escuela & injured & lesionado/a \\
\hline intellect & intelecto & perjury & perjurio \\
\hline ivy & hiedra & powerful & poderoso/a \\
\hline journalist & periodista & problem & problema \\
\hline law & ley & quantity & cuantidad \\
\hline
\end{tabular}


DCT in Spanish spatial demonstratives Todisco, Rocca \& Wallentin (2021)

\begin{tabular}{|l|l|l|l|}
\hline lightning & relámpago & rally & rally \\
\hline liked & apreciado/a & rum & ron \\
\hline lip & labio & scooter & moto \\
\hline loan & préstamo & sled & trineo \\
\hline monkey & mono & store & almacén \\
\hline mystery & misterio & storm & tormenta \\
\hline office & oficina & toaster & tostadora \\
\hline optimism & optimismo & tree & árbol \\
\hline pan & sartén & truth & verdad \\
\hline party & fiesta & victim & víctima \\
\hline pencil & lápiz & woe & aflicción \\
\hline penguin & pingüino & wonder & asombro \\
\hline
\end{tabular}

